\title{
Hepatitis $C$ in Lebanon: the burden of the disease and the value of comprehensive screening and
} treatment

\author{
Antoine Abou Rached' \\ Selim Abou Kheir' \\ Jowana Saba' \\ Salwa Assaf ${ }^{2}$ \\ Georges Kassis ${ }^{3}$ \\ Yuri Sanchez Gonzalez ${ }^{4}$ \\ Olivier Ethgen ${ }^{5,6}$
}

'Faculty of Medicine, School of Medicine, Lebanese University, Beirut, Lebanon; ${ }^{2}$ Abbvie Biopharmaceuticals $\mathrm{GmbH}$, Beirut, Lebanon; ${ }^{3}$ Abbvie Biopharmaceuticals, Paris, France; ${ }^{4}$ AbbVie Inc., North Chicago, IL, USA; ${ }^{5}$ SERFAN Innovation, Namur, Belgium; ${ }^{6}$ Department of Public Health, Epidemiology and Health Economics, University de Liège, Liège, Belgium

Correspondence: Antoine Abou Rached Department of Internal Medicine, School of Medicine, Lebanese University, P.O. Box \#3, Hadath, Beirut 2903 I308, Lebanon

Tel +9613746317

Email abourachedantoine@gmail.com
This article was published in the following Dove Press journal: Hepatic Medicine: Evidence and Research

Purpose: To analyze the hepatitis $\mathrm{C}$ virus (HCV) burden in Lebanon and the value of comprehensive screening and treatment for different age groups and fibrosis stages.

Methods: We used a multicohort, health-state-transition model to project the number of HCV genotype 1 and 4 patients achieving a sustained virologic response 12 weeks after treatment or progressing to compensated cirrhosis (CC), decompensated cirrhosis (DCC), hepatocellular carcinoma (HCC), or liver-related death (LrD) from 2016 to 2036. In the low/medium/high screening scenarios, the proportion of patients screened for $\mathrm{HCV}$ was projected to increase to $60 \% / 85 \% / 99 \%$, respectively, by 2036 . We analyzed four treatment strategies: 1) no treatment, 2) all-oral direct-acting antivirals (DAAs) given to F3-F4 (CC) patients only, 3) all-oral DAAs to F2-F3-F4 (CC) patients, and 4) all-oral DAAs to all fibrosis patients.

Results: Low, medium, and high HCV screening scenarios projected that 3,838, 5,665, and 7,669 individuals will be diagnosed with HCV infection, respectively, from 2016 to 2036 , or $40 \%$ of those aged $18-39$ years, and $60 \%$ of those aged $40-80$ years. With no treatment, the projected number of patients reaching CC, DCC, HCC, or LrD in 2036 was 899, 147, 131, and 147, respectively, for the 18-39 years age group. For the $40-80$ years age group, these projections were substantially greater: 2,828 CC, 736 DCC, $668 \mathrm{HCC}$, and $958 \mathrm{LrD}$. The overall economic burden without treatment reached 150 million EUR. However, introducing DAAs for F0-F4 patients was projected to increase the proportion of remaining life-years spent in sustained virologic response 12 weeks after treatment by $43 \%$ and $62 \%$ compared to DAAs given at F2-F4 or F3-F4 only, respectively. Conclusion: An enhanced screening policy combined with broader access to DAAs can diminish the future clinical and economic burden of HCV in the Lebanese population and, for the middle-aged and elderly, provide the greatest health benefit with net cost savings.

Keywords: hepatitis C, epidemiology, burden of disease, screening, Lebanon, HCV treatment, screening and treatment policies

\section{Introduction}

Hepatitis $\mathrm{C}$ virus (HCV) infections are a major health problem. Prevalence is $2.3 \%$ and $1.5 \%$ in World Health Organization (WHO) Eastern Mediterranean and European Regions, respectively, and there are 71 million people with chronic HCV infections worldwide. ${ }^{1}$ Approximately $75 \%-85 \%, 60 \%-70 \%$, and $5 \%-20 \%$ of people infected with HCV will develop chronic hepatitis, hepatic steatosis or fibrosis, and cirrhosis, respectively. Also, 1\%-5\% of people acutely infected with HCV will incur life-threatening complications and hepatocellular carcinoma (HCC) within 20 years. $^{2}$

Lebanon is a low endemic region for hepatitis $\mathrm{C}$, with a prevalence of $0.2 \%$ in the general population. ${ }^{3}$ The viremic rate is $75 \% .^{3}$ People over 40 years have the highest

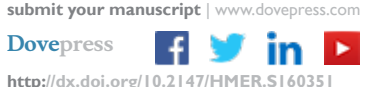


prevalence and are at the most advanced fibrosis stage. ${ }^{4}$ Genotype 1 is the most prevalent genotype ( $80 \%$ is genotype $1 b$ ), followed by genotype 4 , representing together $>80 \%$ of the total infected population. ${ }^{5}$

Eradicating $\mathrm{HCV}$ is the most effective way to reduce the incidence of liver decompensation and HCC. ${ }^{6}$ In addition, chronic hepatitis $\mathrm{C}(\mathrm{CHC})$ is a systemic condition associated with extrahepatic manifestations such as diabetes mellitus, cardiovascular disease, psychiatric disorders, renal dysfunction, and rheumatologic conditions. ${ }^{7}$

The treatment of HCV infection has undergone profound and rapid innovation. For more than two decades, administering interferon (IFN) alpha in combination with ribavirin was the basis of all HCV therapies, to which $30 \%-90 \%$ of patients responded. ${ }^{8}$ By 2017, the Food and Drug Administration and the European Medical Agency had approved eight all-oral, interferon-free direct-acting antiviral (IFN-free DAA) regimens to treat different genotypes. The sustained virologic response (SVR) rates in pivotal Phase II and III trials were between $92 \%$ and $100 \%$, even in pretreated HCV genotype 1-infected patients. ${ }^{9}$ For most patients, treatment is now possible with highly effective, safe, and tolerable combinations of oral DAAs.

The eradication of hepatitis $\mathrm{C}$ is currently considered as within reach, but pricing and funding remain important barriers to treatment access. The prices of DAAs have caused public discussion in most countries and the commitment to fund comprehensive elimination campaigns remains low. ${ }^{10}$ Nonetheless, recent studies have indicated that for genotype 1 the current all-oral DAA-based regimens are cost-effective. ${ }^{11}$ And if we consider, in addition to liver-related clinical outcomes, extrahepatic complications, HCV therapy could be even more cost-effective. ${ }^{12}$

HCV infections have been shown to impose a high economic burden on the US health care system, individuals, and society. ${ }^{13}$ Recent simulation studies have estimated that the clinical and economic burdens of HCV will continue to increase over the next two decades. ${ }^{14-16}$ Despite this burden, the vast majority of $\mathrm{HCV}$-infected patients remain undiagnosed and, therefore, not appropriately managed. ${ }^{17}$ This is troubling given the availability of highly effective therapy, as described above. Given the heavy economic burden of HCV, it is important to understand the direct costs attributable to HCV infection, complications, and treatment to better clarify the value and cost-effectiveness of new treatments.

The aim of this study was to estimate the HCV burden in Lebanon and the potential benefits of different screening and treatment strategies that leverage novel antiviral agents compared to older IFN-based treatments.

\section{Methods}

We have analyzed the HCV data from the published literature on $\mathrm{HCV}$ in Lebanon, including prevalence, genotypic distribution, degree of liver fibrosis, progression of $\mathrm{CHC}$, treatment efficacy and cost, as well as cost and complications of liver disease. We constructed a mathematical model of CHC progression to examine the effectiveness of different screening and treatment policies over the next 20 years, on the progression of fibrosis gradually develops stage-by-stage in those with chronic infection than cirrhosis that progresses to decompensated cirrhosis (DCC) stage over time.

\section{Target population}

The Lebanese population was selected and divided into two age groups: $18-39$ and 40-80 years. The age distribution of the population was retrieved from the Lebanese Ministry of Public Health statistics bulletin of 2013. Using the national growth rate and an open sequential multicohort model, projections were conducted from 2016 to 2036 for the two groups.

\section{Model structure}

The multicohort model was designed using Microsoft Excel ${ }^{\circledR}$. It forecasts population health outcomes for different treatment strategies adjusted by the defined HCV screening scenario. The $\mathrm{CHC}$ natural history used in the model is shown in Figure 1.

The natural history of CHC was modeled through a health-state-transition process. A Markov model simulating chronic HCV progression was used to estimate disease treatment costs and hepatic outcomes over patients' lifetimes. At the time of screening, the identified CHC subjects were allocated to the diagnosed fibrosis stages F0-F4/compensated cirrhosis (CC). The subjects then progressed annually from fibrosis stage F0 to F4/CC and to DCC and/or HCC. Subjects could also die from background mortality from any health state. It was assumed that death from DCC, HCC, or liver transplant (LT) constituted a liver-related death $(\mathrm{LrD})$.

For simplicity, the model assumed an overall rate of screening that takes into account the different screening and diagnosis steps. For instance, a rate of $10 \%$ means that the HCV status (genotype and fibrosis stage) is known for $10 \%$ of the individuals who tested positive.

Each year, a new cohort of patients diagnosed with GT1-4 CHC was added to the previous cohort as the overall population became increasingly screened over the 2016-2036 period. Each cohort evolved through the $\mathrm{CHC}$ health-state-transition model described above (Figure 1), 


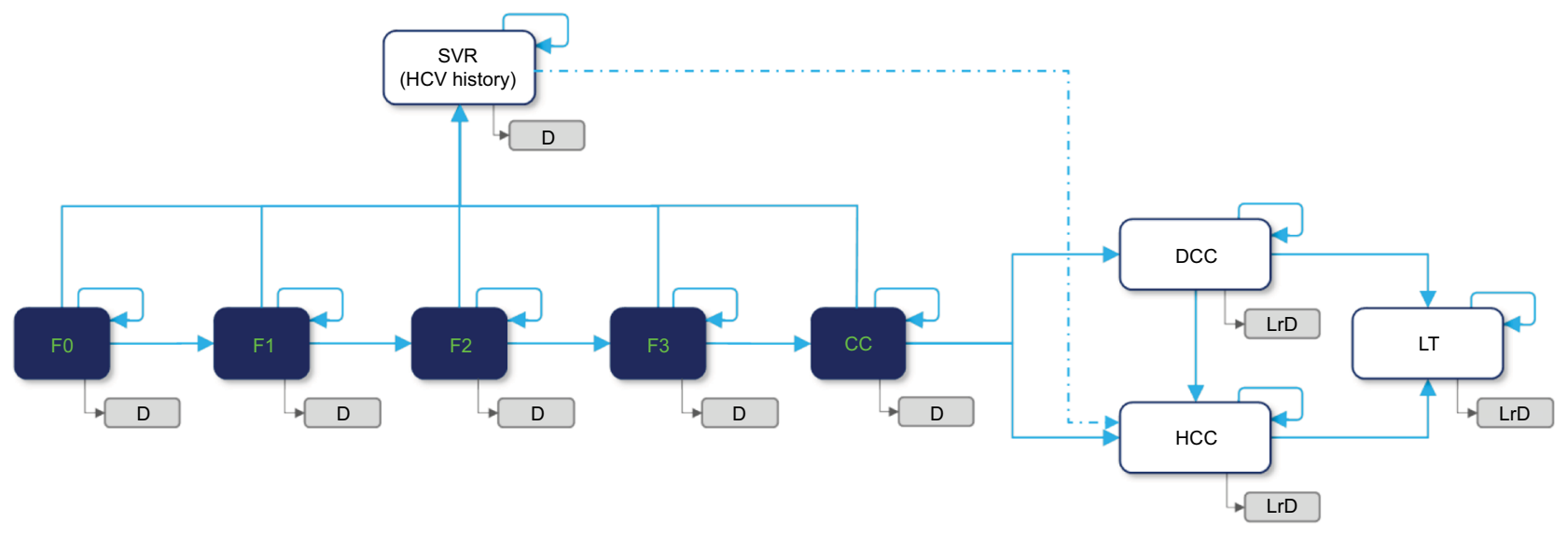

Figure I Model schematic of the natural history of chronic hepatitis $\mathrm{C}$.

Notes: F0-F3, Metavir fibrosis score 0-3.

Abbreviations: CC, compensated cirrhosis (Metavir fibrosis score F4); D, all-cause death; DCC, decompensated cirrhosis; HCC, hepatocellular carcinoma; HCV, hepatitis $C$ virus; LrD, liver-related death (ie, death from DCC, HCC, or LT); LT, liver transplant; SVR, sustained virologic response.

with transition probabilities adjusted for the respective treatment effectiveness. Each year, the model computed the number of patients in each health state within the treated CHC population.

\section{Prevalence and fibrosis distribution}

A recent study showed that the prevalence of hepatitis $\mathrm{C}$ in the Lebanese general population was $0.2 \%{ }^{3}$ and the highest prevalence was in people older than 60 years $(0.55 \%)$, followed by those aged $40-60$ years $(0.37 \%){ }^{4}$ Also, fibrosis severity was recently studied in Lebanon, with differences noted between different age groups. Advanced fibrosis was seen in $6.4 \%$ of people aged $<40$ years, in $45 \%$ of those aged $40-60$ years, and in $83.5 \%$ of those aged $>60$ years ${ }^{4}$ (Table 1).

For simplicity, we divided our population into two groups: 18-39 years, reflecting in majority the population of drug users and $40-80$ years, reflecting the baby-boomer population (Table 1).

\section{Screening scenarios}

Three HCV screening scenarios were used for the following groups: low, medium, and high variants. The medium variant corresponded to the mean between the low and the high variant. The screening scenarios were defined for the following 20 years (from 2016 to 2036) by setting five-point estimates (2016, 2021, 2026, 2031, and 2036), each corresponding to a 5 -year average screening rate. These estimates capture the forecasted/targeted cumulative rates of $\mathrm{HCV}$ awareness among the survivors of the selected population at the respective dates. As the model uses a yearly cycle, a logistic regression was fitted to these five estimates to yield
Table I Proportion of patients in each fibrosis stage

\begin{tabular}{lll}
\hline Fibrosis stage & $\mathbf{1 8 - 3 9}$ years age group & $\mathbf{4 0 - 8 0}$ years age group \\
\hline F0 & $65.0 \%$ & $9.5 \%$ \\
FI & $23.2 \%$ & $14.2 \%$ \\
F2 & $5.3 \%$ & $12.2 \%$ \\
F3 & $2.6 \%$ & $13.5 \%$ \\
F4 & $3.9 \%$ & $50.7 \%$ \\
\hline
\end{tabular}

yearly cumulative rates of HCV screening. Figure 2 shows the screenings used for the two groups.

\section{Disease progression}

Annual transition probabilities were taken from multiple sources in the literature (Table 2).

\section{Treatments' effectiveness}

Table 3 shows the different sustained virologic responses 12 weeks after treatment $\left(\mathrm{SVR}_{12} \mathrm{~s}\right)$ that were assumed according to the therapy and liver fibrosis stages. All estimates were taken from randomized clinical trials.

\section{Treatments of adverse events}

Only severe adverse events from the various treatment regimens were considered: severe anemia, severe depression, and severe rash. The incidence estimates of severe adverse events were taken from a recent French modeling study. ${ }^{18}$

\section{Health care costs and perspective}

Only direct inpatient and outpatient medical costs were considered. They are the costs of HCV screening, therapy, adverse events, fibrosis stages, LrDs, and liver complications (DCC, HCC, and liver transplantation). The 2014 and 
A

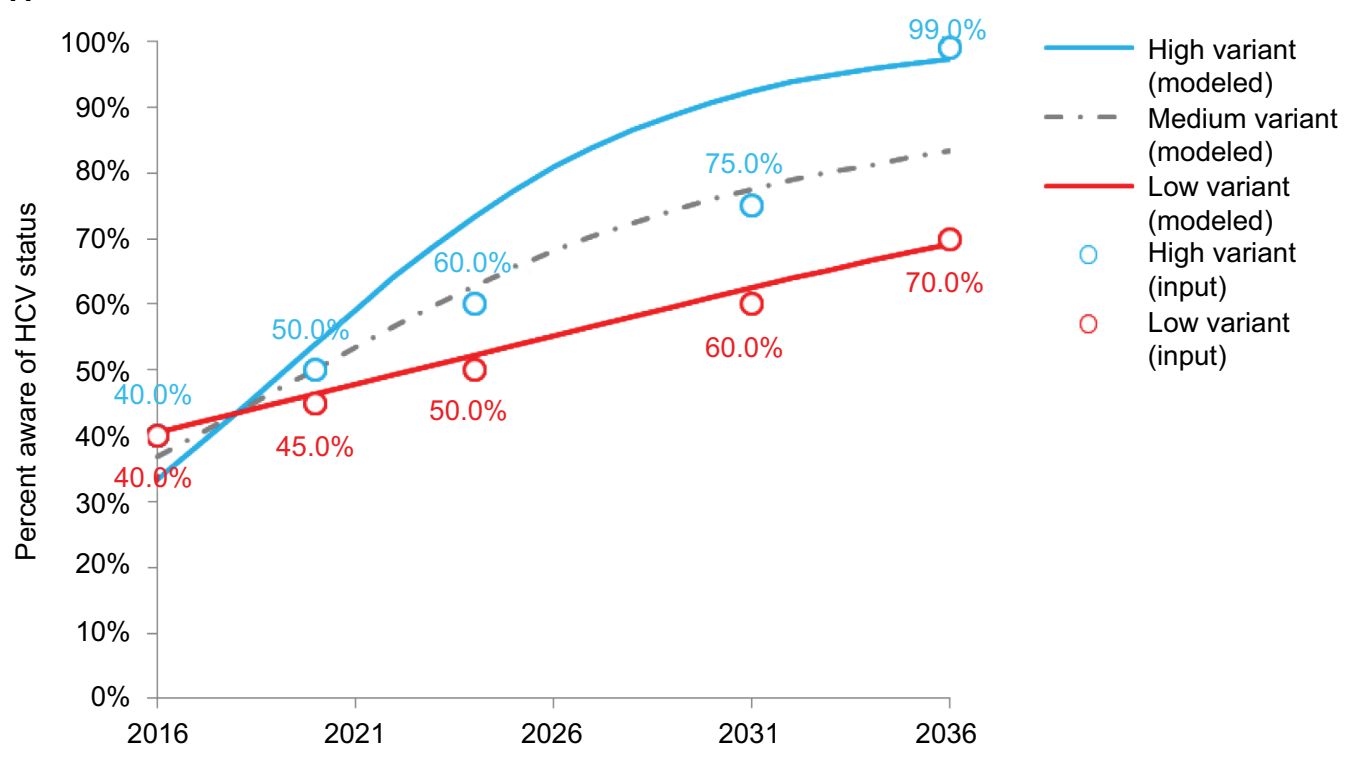

B

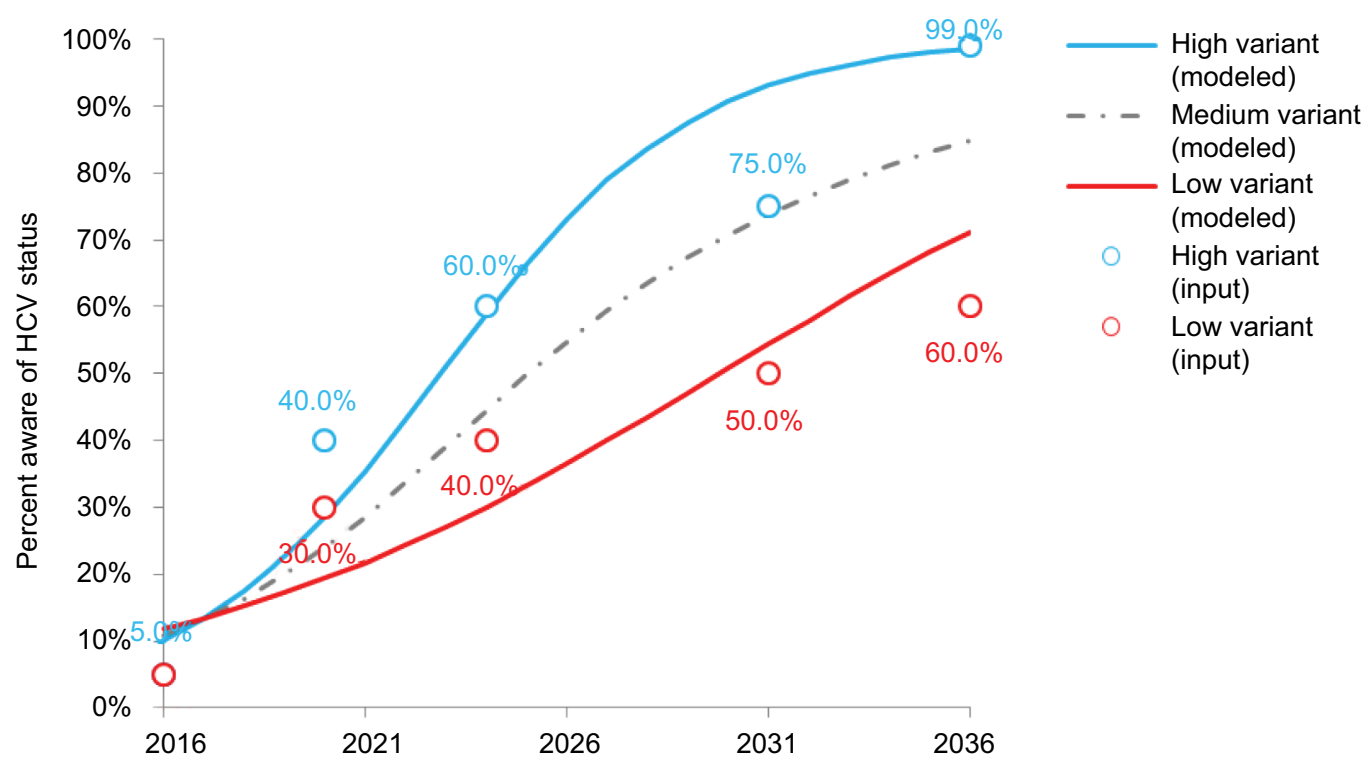

Figure 2 Screening scenario in the 18-39 (A) and 40-80 years age groups (B).

Abbreviation: $\mathrm{HCV}$, hepatitis $\mathrm{C}$ virus.

2015 average costs from major health insurance claims were collected. The model used the perspective of the Lebanese health care system.

\section{Base-case analysis}

Newly diagnosed patients received either all-oral, IFN-free DAAs or no treatment, depending on their fibrosis stage (ie, treatment strategy A, B, C, or D). We compared four treatment strategies for the two age groups: A, no treatment at all; B, alloral, IFN-free DAAs given to F3-F4 patients only; C, all-oral, IFN-free DAAs given to F2-F3-F4 patients only; and D, alloral, IFN-free DAAs given to all, ie, F0-F1-F2-F3-F4 patients.
The model forecasted and compared the number of patients reaching SVR, DCC, HCC, and LT health states for the four treatment strategies. Likewise, the number of life-years (LYs) spent in each health state and the number of LrDs were computed and compared. Population-level health outcomes were also presented as the percentage of years lived under each health state (SVR, DCC, HCC, and LT) out of the total number of years lived by these selected population.

\section{Sensitivity analysis}

One-way deterministic sensitivity analyses were carried on the costs of treatment per LY spent in $\mathrm{SVR}_{12}$ for each 
treatment strategy. All model parameters were varied within $\pm 20 \%$ ranges subject to plausibility check (ie, the transition probabilities could not be $<0$ or $>1$ ). The distribution of fibrosis stages was varied between a "mild" scenario (F0: 96\%, F1: 1\%, F2: 1\%, F3: 1\%, and F4: 1\%) and a "severe" scenario (F0: 1\%, F1: 1\%, F2: 1\%, F3: 1\%, and F4: 96\%) in comparison to the baseline distribution. We also assessed outcomes in the "low" and "high" screening scenarios and varied the discount rate from $0 \%$ to $5 \%$ for future costs and LYs in $\mathrm{SVR}_{12}$. The impact of the 10 most influential parameters was plotted on tornado diagrams, as appropriate.

\section{Results}

\section{Size of the GTI - and GT4-diagnosed populations initiated on treatment}

Table 4 shows the predicted number of newly diagnosed HCV patients over the 2016-2036 time periods according to the three screening variants and two age groups. The

Table 2 Annual transition probabilities in different studies

\begin{tabular}{|c|c|c|c|}
\hline Health states & & Input & References \\
\hline \multirow[t]{2}{*}{$\mathrm{F} 0 \rightarrow$} & $\mathrm{FI}$ & 0.117 & Thein et $\mathrm{al}^{54}(2008)$ \\
\hline & SVR & 0.000 & Assumption \\
\hline $\mathrm{FI} \rightarrow$ & F2 & 0.085 & Thein et $\mathrm{al}^{54}(2008)$ \\
\hline $\mathrm{F} 2 \rightarrow$ & F3 & 0.120 & Thein et $\mathrm{al}^{54}(2008)$ \\
\hline $\mathrm{F} 3 \rightarrow$ & $\mathrm{CC}$ & 0.116 & Thein et $\mathrm{al}^{54}(2008)$ \\
\hline \multirow[t]{2}{*}{$\mathrm{CC} \rightarrow$} & DCC & 0.040 & Liu et $\mathrm{al}^{55}(2012)$ \\
\hline & $\mathrm{HCC}$ & 0.034 & Alazawi et al ${ }^{56}(2010)$ \\
\hline \multirow[t]{3}{*}{$\mathrm{DCC} \rightarrow$} & $\mathrm{HCC}$ & 0.020 & Liu et $\mathrm{a}^{55}(2012)$ \\
\hline & LT & 0.017 & Razavi et al ${ }^{57}(2013)$ \\
\hline & LrD & 0.260 & Liu et a $\left.\right|^{55}(2012)$ \\
\hline \multicolumn{4}{|l|}{$\mathrm{HCC}$} \\
\hline \multirow[t]{2}{*}{ Ist year $\rightarrow$} & LT & 0.017 & Razavi et al ${ }^{57}(2013)$ \\
\hline & $\operatorname{LrD}$ & 0.410 & Singal et $\mathrm{a}^{58}(2010)$ \\
\hline \multirow[t]{2}{*}{ Subsequent year $\rightarrow$} & $\mathrm{LT}$ & 0.017 & Razavi et al ${ }^{57}(2013)$ \\
\hline & LrD & 0.190 & Singal et $\mathrm{a}^{58}(2010)$ \\
\hline \multicolumn{4}{|l|}{ LT } \\
\hline Ist year $\rightarrow$ & LrD & 0.117 & Thuluvath et $\mathrm{al}^{59}(2010)$ \\
\hline Subsequent year $\rightarrow$ & LrD & 0.056 & Thuluvath et $\mathrm{al}^{59}(2010)$ \\
\hline
\end{tabular}

Notes: F0-F3, Metavir fibrosis score 0-3.

Abbreviations: CC, compensated cirrhosis (Metavir fibrosis score F4); D, allcause death; DCC, decompensated cirrhosis; HCC, hepatocellular carcinoma; LrD, liver-related death (ie, death from DCC, HCC, or LT), LT, liver transplant; SVR, sustained virologic response. low, medium, and high HCV screening scenarios showed, respectively, that $1,621,2,526$, and 3,432 individuals aged 18-39 years in 2016 would be diagnosed with HCV infections between 2016 and 2036 compared to 2,217, 3,139, and 4,237 individuals aged $40-80$ years.

\section{Burden of illness and public health impact in Lebanon}

In the high screening scenario with no treatment given, the number of patients reaching CC, DCC, HCC, and $\mathrm{LrD}$ in 2036 are summarized in Figure 3 in the two age groups.

The cumulative health care cost secondary to HCV will continue to increase during the next 20 years. The cost of HCV complications is summarized in Figure 4 for the two age groups.

When introducing oral DAAs at different strategies, the number of life years lived with $\mathrm{SVR}_{12}$ during 2016-2036 is

Table 4 Newly diagnosed HCV patients between 2016 and 2036 in the $18-39$ and $40-80$ age groups

\begin{tabular}{|c|c|c|c|}
\hline \multirow[t]{2}{*}{$\begin{array}{l}\text { Health } \\
\text { states }\end{array}$} & \multicolumn{3}{|c|}{$\begin{array}{l}\text { New patients diagnosed with HCV infection } \\
\text { between } 2016 \text { and } 2036\end{array}$} \\
\hline & $\begin{array}{l}\text { I8-39 years age } \\
\text { group }\end{array}$ & $\begin{array}{l}40-80 \text { years age } \\
\text { group }\end{array}$ & Overall \\
\hline \multicolumn{4}{|c|}{ Low variant } \\
\hline F0 & 283 & 90 & 373 \\
\hline $\mathrm{FI}$ & 572 & 325 & 897 \\
\hline F2 & 353 & 342 & 695 \\
\hline F3 & 234 & 421 & 655 \\
\hline $\mathrm{CC}$ & 180 & 1,039 & 1,219 \\
\hline Total & 1,621 & 2,217 & 3,838 \\
\hline \multicolumn{4}{|c|}{ Medium variant } \\
\hline F0 & 511 & $|4|$ & 652 \\
\hline $\mathrm{FI}$ & 919 & 482 & $\mathrm{I}, 40 \mathrm{I}$ \\
\hline F2 & 524 & 488 & 1,012 \\
\hline F3 & 323 & 582 & 905 \\
\hline $\mathrm{CC}$ & 250 & $\mathrm{I}, 445$ & 1,695 \\
\hline Total & 2,526 & 3,139 & 5,665 \\
\hline \multicolumn{4}{|c|}{ High variant } \\
\hline FO & 739 & 196 & 935 \\
\hline $\mathrm{FI}$ & 1,267 & 658 & 1,925 \\
\hline F2 & 695 & 660 & $\mathrm{I}, 355$ \\
\hline F3 & 411 & 780 & I,I9I \\
\hline $\mathrm{CC}$ & 320 & 1,943 & 2,263 \\
\hline Total & 3,432 & 4,237 & 7,669 \\
\hline
\end{tabular}

Abbreviations: $\mathrm{CC}$, compensated cirrhosis; $\mathrm{HCV}$, hepatitis $\mathrm{C}$ virus.

Table 3 Different $\mathrm{SVR}_{12}$ s assumed according to therapy and liver fibrosis stage

\begin{tabular}{lllllll}
\hline Therapy & F0 & FI & F2 & F3 & CC & References \\
\hline IFN+RBV & $45.6 \%$ & $45.6 \%$ & $43.5 \%$ & $43.5 \%$ & $33.3 \%$ & Jacobson et al $^{60}(201 \mathrm{I})$ \\
IFN+RBV+PI & $65.9 \%$ & $65.9 \%$ & $65.9 \%$ & $65.9 \%$ & $31.3 \%$ & Poordad et al $^{61}(201 \mathrm{I})$ \\
IFN-based DAA & $91.7 \%$ & $91.7 \%$ & $91.7 \%$ & $91.7 \%$ & $80.8 \%$ & Lawitz et al $^{62}(2013)$ \\
All-oral DAA & $97.0 \%$ & $97.0 \%$ & $97.0 \%$ & $97.0 \%$ & $97.0 \%$ & Ferenci et al $^{63}(2014)$, Feld et al \\
\hline
\end{tabular}

Abbreviations: DAA, direct-acting antiviral; IFN, interferon, PI, protease inhibitor; RBV, ribavirin; SVR $_{12}$, sustained virologic response 12 weeks after treatment. 

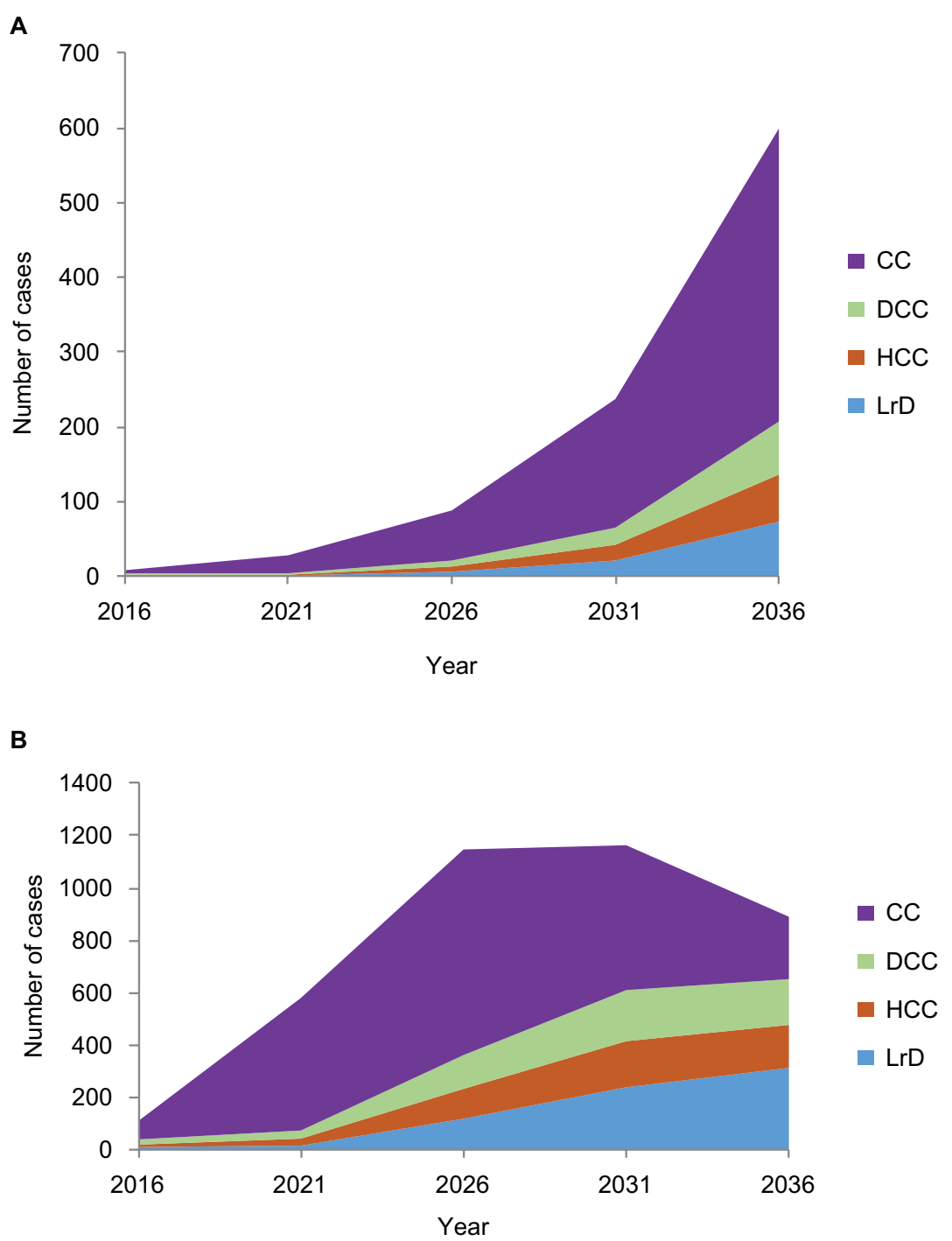

Figure 3 Hepatic complications from HCV (cumulative cases) for the 18-40 (A) and 40-80 years age groups (B).

Abbreviations: CC, compensated cirrhosis; DCC, decompensated cirrhosis; HCC, hepatocellular carcinoma; HCV, hepatitis C virus; LrD, liver-related death.

dramatically improved (Table 5). All-oral DAAs for F0-F4 patients aged 18-39 increased the proportion of the remaining LYs spent in SVR by $31 \%$ and $53 \%$ compared to all-oral, IFN-free DAAs given to F2-F4 or to F3-F4, respectively. Similarly, all-oral DAAs for F0-F4 patients aged 40-80 years also increased the remaining LYs spent in SVR compared to alloral, IFN-free DAAs given to F2-F4 or to F3-F4, respectively.

\section{Budget impact and return on investment}

The treatment, adverse event, and medical costs to the health care system of the four treatment strategies are shown in Table 6. The all-oral, IFN-free DAAs for the F0-F4 strategy have the greatest cost impact as they are used in a greater number of patients, with the largest impact in the 18-39 age group.
Table 7 summarizes the return on investment and compares the percentage of person LYs spent in SVR and the budget impact of the four treatment strategies considered over the 2016-2036 time frame. The all-oral, IFN-free DAAs for F0-F4 increased the cost of HCV treatment but considerably increased the health benefit at the population level (ie, drastic increase in the proportion of LYs spent in SVR compared to other strategies). According to the model, adopting the high screening variant and all-oral, IFN-free DAAs for the entire 18-39 age group would cost 1,957 EUR for a life year gained in $\mathrm{SVR}_{12}$ compared to no treatment and screening. For the $40-80$ age group, there would be a cost savings of -168 Euro/LY spent in $\mathrm{SVR}_{12}$ compared to no treatment strategy. 


\section{A}

Cumulative health care cost (18-39 years)

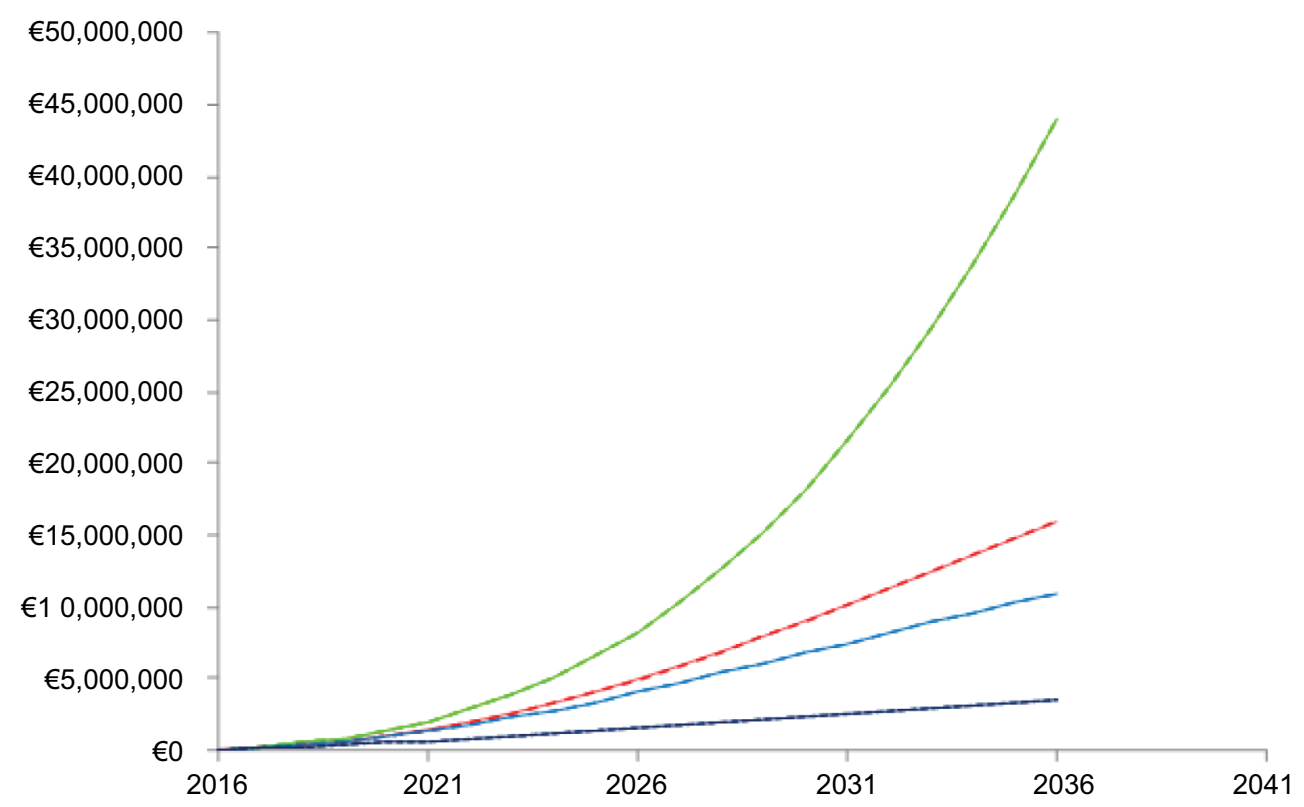

B

Cumulative health care cost (40-80 years)

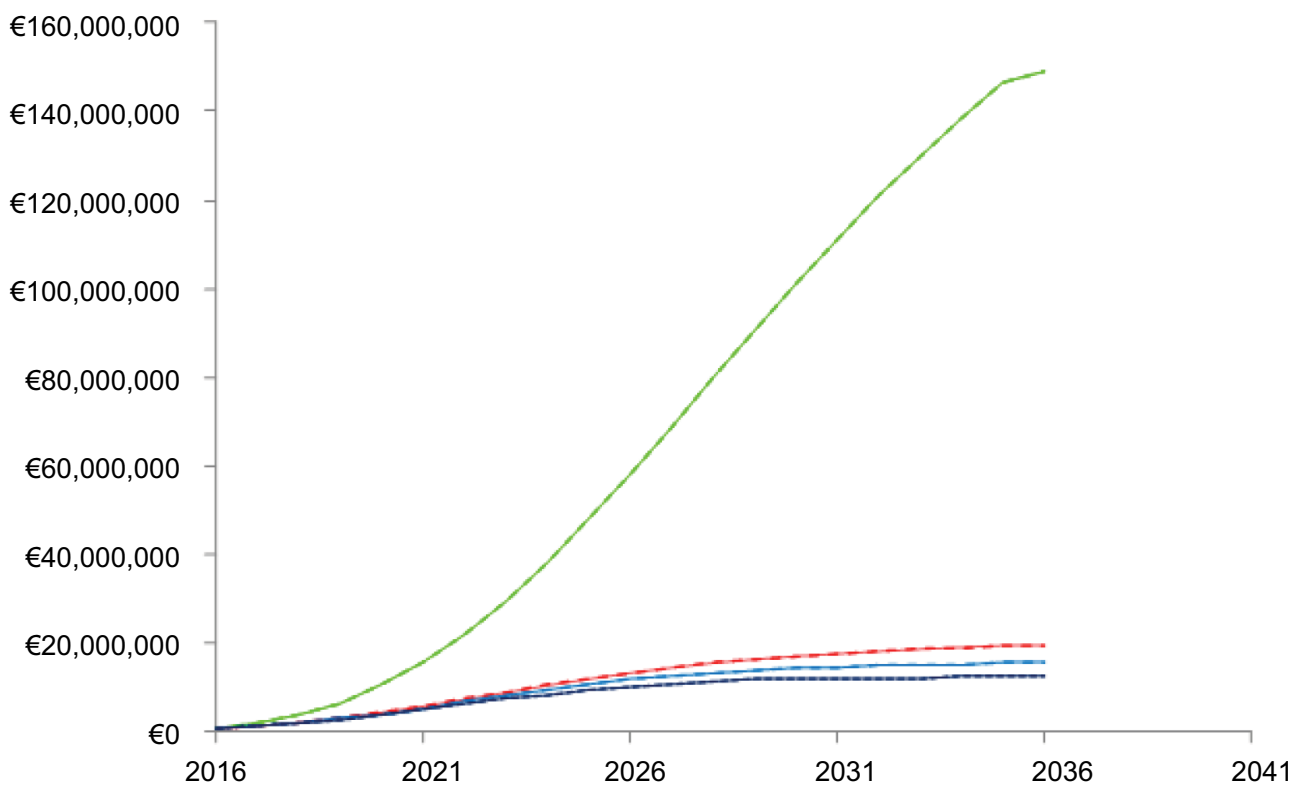

Figure 4 Cumulative cost of HCV complications in the 18-39 (A) and 40-80 years age groups (B).

Note: A, no treatment at all; B, alloral, IFN-free DAAs given to F3-F4 patients only; C, all-oral, IFN-free DAAs given to F2-F3-F4 patients only; and D, all oral, IFN-free DAAs given to all, ie, F0-FI-F2-F3-F4 patients. (Strategy A, green; Strategy B, red; Strategy C, blue; Strategy D, navy blue).

Abbreviation: $\mathrm{HCV}$, hepatitis $\mathrm{C}$ virus.

\section{Sensitivity analysis}

The results of the one-way deterministic sensitivity analysis on the cost of treatment/LYs in $\mathrm{SVR}_{12}$ for all-oral, IFN-free DAAs for F0-F4 are shown in Figure 5. Results were most sensitive to changes in the screening scenario, fibrosis distribution, and, to a lower extent, DAA efficacy.

\section{Discussion}

In this study, we explored the impact of providing antiviral treatment to a larger proportion of persons with $\mathrm{HCV}$ infection under different screening scenarios. According to the model, concerning the screening strategy, the high screening scenario will be able to detect $>90 \%$ of the total population 
Table 5 Clinical burden - number and percent of life-years spent in SVR

\begin{tabular}{lllll}
\hline & $\begin{array}{l}\text { No } \\
\text { treatment, } \\
\text { value (\%) }\end{array}$ & $\begin{array}{l}\text { All-oral, IFN-free } \\
\text { DAAs for F3-F4, } \\
\text { value (\%) }\end{array}$ & $\begin{array}{l}\text { All-oral, IFN-free } \\
\text { DAAs for F2-F4, } \\
\text { value (\%) }\end{array}$ & $\begin{array}{l}\text { All-oral, IFN-free } \\
\text { DAAs for F0-F4, } \\
\text { value (\%) }\end{array}$ \\
\hline $\begin{array}{llll}\text { I8-39 years group } \\
\text { Number of patients who achieved SVR }\end{array}$ & $0(0)$ & $1,458(42.5)$ & $2,213(64.5)$ & $3,274(95.4)$ \\
From F0 & $0(0)$ & $0(0)$ & $0(0)$ & $727(22.2)$ \\
From FI & $0(0)$ & $0(0)$ & $0(0)$ & $1,223(37.4)$ \\
From F2 & $0(0)$ & $0(0)$ & $1,545(69.8)$ & $656(20.0)$ \\
From F3 & $0(0)$ & $1,167(80.1)$ & $378(17.1)$ & $378(11.5)$ \\
From F4 & $0(0)$ & $291(19.9)$ & $291(13.1)$ & $291(8.9)$ \\
40-80 years group & & & & \\
Number of patients who achieved SVR & $0(0)$ & $3,321(78.4)$ & $3,744(88.4)$ & $4,154(98.0)$ \\
From F0 & $0(0)$ & $0(0)$ & $0(0)$ & $192(4.6)$ \\
From FI & $0(0)$ & $0(0)$ & $0(0)$ & $645(15.5)$ \\
From F2 & $0(0)$ & $0(0)$ & $1,074(28.7)$ & $646(15.6)$ \\
From F3 & $0(0)$ & $1,415(42.6)$ & $764(20.4)$ & $7,906(50.9)$ \\
From F4 & $0(0)$ & $1,906(57.4)$ & & $1,906(45.9)$ \\
\hline
\end{tabular}

Abbreviations: DAA, direct-acting antiviral; IFN, interferon; SVR, sustained virologic response.

Table 6 Economic burden - health care costs

\begin{tabular}{|c|c|c|c|}
\hline & $\begin{array}{l}\text { HCV-related overall costs } \\
\text { (18-39 years) (EUR) }\end{array}$ & $\begin{array}{l}\text { HCV-related overall costs } \\
\text { (40-80 years) (EUR) }\end{array}$ & $\begin{array}{l}\text { Total HCV-related } \\
\text { overall costs (EUR) }\end{array}$ \\
\hline \multicolumn{4}{|l|}{ No treatment } \\
\hline Medical & $44,097,060$ & $149,004,066$ & $193,101,126$ \\
\hline Serious adverse events & 0 & 0 & 0 \\
\hline Treatment & 0 & 0 & 0 \\
\hline Total & $44,097,060$ & $149,004,066$ & $193,101,126$ \\
\hline All-oral, IFN-free DAAs for F3-F4 & & & 0 \\
\hline Medical & $15,928,504$ & $19,429,436$ & $35,357,940$ \\
\hline Serious adverse events & 0 & 0 & 0 \\
\hline Treatment & $48,507,649$ & $102,867,974$ & $151,375,623$ \\
\hline Total & $64,436,153$ & $122,297,410$ & $186,733,563$ \\
\hline All-oral, IFN-free DAAs for F2-F4 & & & 0 \\
\hline Medical & $10,978,004$ & $15,485,609$ & $26,463,613$ \\
\hline Serious adverse events & 0 & 0 & 0 \\
\hline Treatment & $71,784,150$ & $115,302,946$ & $187,087,096$ \\
\hline Total & $82,762,154$ & $130,788,555$ & $213,550,709$ \\
\hline All-oral, IFN-free DAAs for F0-F4 & & & 0 \\
\hline Medical & $3,539,699$ & $|2,4| 0,630$ & $15,950,329$ \\
\hline Serious adverse events & 0 & 0 & 0 \\
\hline Treatment & $102,946,279$ & $127, \mid 14,860$ & $230,061,139$ \\
\hline Total & $106,485,978$ & $139,525,490$ & $246,011,468$ \\
\hline
\end{tabular}

Abbreviations: DAA, direct-acting antiviral; $\mathrm{HCV}$, hepatitis $\mathrm{C}$ virus; IFN, interferon.

infected with HCV. According to the model, the proportion of patients with advanced HCV-related liver diseases will increase between 2016 and 2036. This phenomenon is due to the aging of the infected population and the resultant progression of liver fibrosis. The incidences of DCC, HCC, and LT are expected to peak between 2031 and 2036. Except for $\mathrm{CC}$, the peak is expected in the age group above 40 years between 2026 and 2031 .
We also demonstrated that the burden of hepatitis $\mathrm{C}$ and associated costs will continue to grow over the next 20 years. But, introducing DAAs is projected to improve the life years lived with SVR, especially when all stages of liver fibrosis are treated. If a high screening strategy is adopted, all oral DAAs and the treatment of all liver fibrosis stages will have the best budget impact and the highest return of investment in the different age groups. 
Table 7 The return on investment, the percent of person LYs spent in SVR, and the budget impact of the 4 treatment strategies considered over the 2016-2036 time frame in the 18-39 and the 40-80 years age groups

\begin{tabular}{|c|c|c|c|c|}
\hline & $\begin{array}{l}\text { No } \\
\text { treatment }\end{array}$ & $\begin{array}{l}\text { All-oral, IFN-free } \\
\text { DAAs for F3-F4 }\end{array}$ & $\begin{array}{l}\text { All-oral, IFN-free } \\
\text { DAAs for F2-F4 }\end{array}$ & $\begin{array}{l}\text { All-oral, IFN-free } \\
\text { DAAs for F0-F4 }\end{array}$ \\
\hline \multicolumn{5}{|l|}{$18-39$ years group } \\
\hline \multicolumn{5}{|l|}{ Return on investment (cost of treatment) } \\
\hline Cost of treatment/LYs in SVR 12 & NA & 4,996 EUR & 4,212 EUR & 3,112 EUR \\
\hline$L Y s$ in $S V R_{12} / € 100,000$ & NA & 20.015 & 23.744 & 32.138 \\
\hline$L Y s$ in $S V R_{12} /$ patient who achieved SVR & NA & 6.66 & 7.70 & 10.10 \\
\hline $\mathrm{LYs}_{\mathrm{s}}$ in $\mathrm{SVR}_{12} /$ patient treated & NA & 6.00 & 7.12 & 9.64 \\
\hline \multicolumn{5}{|c|}{ Incremental analysis (incremental cost/LYs gained in $S V R_{12}$ ) } \\
\hline vs. No screening & NA & 2,338 EUR & 2,407 EUR & I,957 EUR \\
\hline vs. No treatment & & 2,095 EUR & 2,269 EUR & I,886 EUR \\
\hline vs. All-oral, IFN-free for F3-F4 & & & 2,498 EUR & I,799 EUR \\
\hline vs. All-oral, IFN-free for F2-F4 & & & & I,479 EUR \\
\hline \multicolumn{5}{|l|}{$40-80$ years group } \\
\hline \multicolumn{5}{|l|}{ Return on investment (cost of treatment) } \\
\hline Cost of treatment/LYs in SVR 12 & NA & 3,062 EUR & 2,924 EUR & 2,76I EUR \\
\hline$L Y s$ in $S V R_{12} / € 100,000$ & NA & 32.658 & 34.204 & 36.218 \\
\hline$L Y s$ in $S V R_{12} /$ patient who achieved SVR & NA & 10.12 & 10.53 & 11.08 \\
\hline $\mathrm{LYs}_{\mathrm{s}}$ in $\mathrm{SVR}_{12} /$ patient treated & NA & 9.80 & 10.26 & 10.87 \\
\hline \multicolumn{5}{|c|}{ Incremental analysis (incremental cost/LYs gained in $S V R_{12}$ ) } \\
\hline vs. No screening & NA & -743 EUR & -417 EUR & -168 EUR \\
\hline vs. No treatment & & -795 EUR & -462 EUR & -206 EUR \\
\hline vs. All-oral, IFN-free for F3-F4 & & & I,453 EUR & I,384 EUR \\
\hline vs. All-oral, IFN-free for F2-F4 & & & & I,324 EUR \\
\hline
\end{tabular}

Abbreviations: DAA, direct-acting antiviral, IFN, interferon; LYs, life-years; NA, not applicable; $S_{V R}$, sustained virologic response 12 weeks after treatment.

We also found that all-oral, IFN-free DAAs for F0-F4 patients can increase by $52 \%$ the number of years that the HCV-infected Lebanese population aged 40-80 years in 2016 will live with $\mathrm{SVR}_{12}$ compared to alternative strategies that leave mild stages of the disease untreated. Our results suggest that an enhanced screening policy, especially for baby boomers, coupled with broader access to all-oral, IFN-free DAAs can diminish the future burden of $\mathrm{HCV}$.

Several studies have already demonstrated the effectiveness and cost-effectiveness of HCV screening. ${ }^{19-21}$ To enhance screening cost-effectiveness, the screening should focus on populations with higher HCV prevalence. ${ }^{20-22}$ However, screening should also be accompanied by effective treatment and quality follow-on care. ${ }^{19}$

We found three cost-effectiveness studies of new all-oral, IFN-free regimens for $\mathrm{CHC}^{18,23,24}$ Hagan et al ${ }^{23}$ reported that new all-oral, IFN-free regimen was cost-effective compared to standard of care in a 50-year-old cohort of $\mathrm{CHC}$ patients. Deuffic-Burban et a ${ }^{18}$ showed that waiting for IFN-free regimens and then treating all patients regardless of their fibrosis stage was the most effective approach, except for F4 patients, and Younossi et $\mathrm{al}^{24}$ determined the cost-effectiveness of IFNcontaining vs. IFN-free regimens to treat HCV GT1-infected patients. Interestingly, they assessed the impact of the treatment decision based on the liver disease stage (staging-guided approach) vs. treat-all approach on the cost-effectiveness of these two regimens. The authors showed that an all-oral, IFNfree regimen for all HCV GT1 patients might be the most cost-effective regimen in this patient population.

As the population with chronic HCV ages, the incidence of advanced liver disease complications (HCC and DCC) is expected to substantially increase, and as the HCV population ages and the costs for treatment increase, the economic burden of chronic HCV infection is expected to grow proportionally with its clinical burden over the next 10-20 years. Previous work examining the direct costs of HCV treatment revealed that $\mathrm{HCV}$ costs were similar to the costs of treating other chronic diseases such as asthma or rheumatoid arthritis. ${ }^{25,26}$ Similarly, other studies showed that the economic burden of $\mathrm{HCV}$ will continue to grow ${ }^{27}$ and that the annual per patient cost burden to payers for chronic HCV exceeds that of more common conditions such as cardiovascular disease $(\$ 18,953)^{28}$ and type 2 diabetes $(\$ 9677) .{ }^{29}$ Despite a decreased rate of in-hospital mortality, the hospital volume and the charges related to hepatitis $\mathrm{C}$ have substantially increased. ${ }^{30}$ Another study demonstrated increasing trends 
A

= Low variant $\quad$ ! High variant

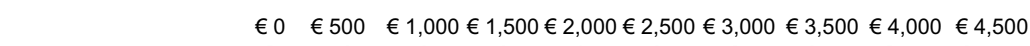

Screening scenario

$€ 3,110$

$€ 3,875$

Distribution of fibrosis stages

$€ 2,810$

$€ 3,355$

All-oral, IFN-free DAAs effectiveness

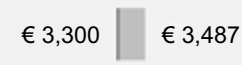

$\mathrm{TP}(\mathrm{F} 3 \rightarrow \mathrm{CC})$

$€ 3,313 \mid € 3,328$

$\mathrm{TP}(\mathrm{F} 2 \rightarrow \mathrm{F} 3)$

$€ 3,314 \mid € 3,326$

$\mathrm{TP}(\mathrm{CC} \rightarrow \mathrm{DCC})$

$€ 3,315 \mid € 3,326$

TP (CC-> HCC)

$€ 3,315 \mid € 3,325$

$\mathrm{TP}(\mathrm{F} 1 \rightarrow \mathrm{F} 2)$

$€ 3,315 \mid € 3,325$

$\mathrm{TP}(\mathrm{F} 0 \rightarrow \mathrm{F} 1)$

$€ 3,318 \mid € 3,322$

Prevalence of genotype $1 \mathrm{alb}$

$€ 3,320$

B

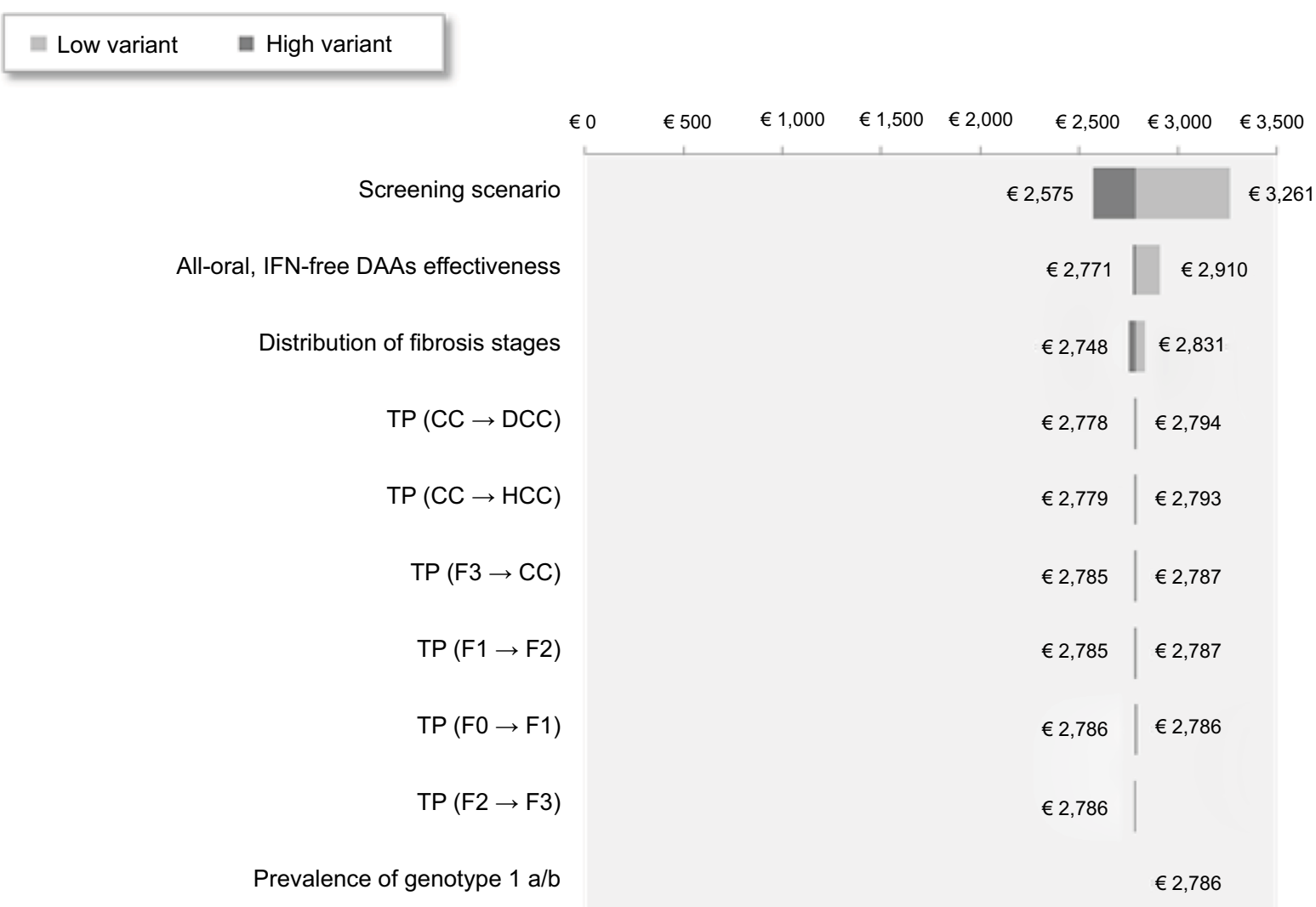

Figure 5 One-way deterministic sensitivity analyses on the cost of treatment/LYs in SVR for all-oral, IFN-free DAAs for F0-F4 in the I8-39 (A) and 40-80 years age groups (B).

Abbreviations: CC, compensated cirrhosis; DAA, direct-acting antiviral; DCC, decompensated cirrhosis; HCC, hepatocellular carcinoma; IFN, interferon; LYs, life-years; SVR, sustained virologic response; TP, transition probability; SVR $_{12}$, sustained virologic response 12 weeks after treatment. 
in hospitalization rates because of $\mathrm{HCV}$ and advanced liver disease between 2004 and 2011, and it showed an 18\%-50\% increase in the average cost of hospitalizations. ${ }^{31}$

For managed care organizations, chronic HCV is a costly disease. Disease-related costs in HCV exceed all-cause costs in demographically matched controls. The direct medical expenditure attributable to chronic HCV in the United States between 2010 and 2019 is expected to be $\$ 10.7$ billion. During this period, HCV may lead to 720,700 years of DCC and HCC and to the loss of 1.83 million years of life in those younger than 65 . Over the 10 years from 2010 through 2019 , the societal cost of premature mortality for those younger than 65 was projected to be $\$ 54.2$ billion, and the cost of morbidity from disability related to DCC and HCC was projected to be $\$ 21.3$ billion. $^{32}$

It was found that increased efforts in $\mathrm{HCV}$ screening and early treatment, particularly before progression to liver cirrhosis, may lead to long-term cost savings in HCV management for managed care systems. ${ }^{27}$ The majority of the models' structure considers patients with SVR to be cured and, therefore, free of progression independent of the level of fibrosis in which such response is reached. A recent study found that achieving SVR can increase survival, reduce liver and extrahepatic morbidity, and lower long-term costs. Even unsuccessful $\mathrm{CHC}$ treatments appear to have a protective effect against mortality and liver morbidity. Treatment with DAAs in early fibrosis stages is generally cost-effective compared to older regimens or late treatment. ${ }^{33}$ Compared to no treatment, all treatments reduce the proportion of patients who progress to cirrhosis, HCC, LT, or death. ${ }^{34-36}$ Therefore, there is compelling clinical and economic evidence that treating patients in early and all fibrosis stages improves survival, reduces liver-related and extrahepatic morbidity, and is cost-effective.

Most notable is the evidence from a review of 38 studies $(n=73,861)$ showing significant mortality benefit of SVR in patients at all fibrosis stages. ${ }^{33} \mathrm{~A}$ systematic review has shown that SVR reduces liver-related mortality (3.3- to 25-fold), HCC incidence (1.7- to 4.2-fold), and hepatic decompensation (2.7- to 17.4-fold). ${ }^{37}$ Another meta-analysis showed that SVR is associated with lower HCV-related morbidity and mortality. ${ }^{38}$ Modeling studies ${ }^{39}$ have confirmed these results by showing that delaying treatment could significantly increase mortality, morbidity, and medical costs. Additionally, there are $>200$ studies showing that chronic HCV infection is associated with several serious extrahepatic manifestations, some of which are associated with high mortality. ${ }^{40,41}$ The incidence of end-stage liver diseases and LRDs can be reduced by focusing treatment on patients with high fibrosis (F3 or F4) but a significant reduction in the total number of infections cannot be achieved unless treatment is expanded to patients in the early stages of fibrosis. The WHO currently recommends that all patients with chronic $\mathrm{HCV}$ should be assessed for treatment, but the challenge is clearly in how to provide treatment at a total cost that health systems and patients can afford. ${ }^{42}$

Our results demonstrate the benefits of treating early stages of fibrosis, which is consistent with evidence published in other patient populations like USA, ${ }^{43}$ Switzerland, ${ }^{44}$ and France. ${ }^{24}$ Another study showed that treatment with sofosbuvir and ledispavir not only reduces HCV-related complications but also is cost-effective for most patients. ${ }^{45}$ Considering the higher acquisition costs, second-generation DAAs are generally cost-effective in treating $\mathrm{CHC}$ patients in many countries. ${ }^{34-36,46,47}$

A systematic review of the economic evaluations of DAAs found that DAAs were either cost-saving or cost-effective in $88 \%$ of analyses. ${ }^{48}$ When other costs (such as productivity losses) are also considered, IFN+RBV-free second-generation DAA regimens were found to be even more cost-effective. ${ }^{34}$ New-generation DAAs offer $90 \%-100 \%$ cure rates, have a significantly better safety profiles, and are treatment options to patients in all stages of liver disease. ${ }^{49}$ Untreated $\mathrm{HCV}$ infection was found to be associated with substantial economic costs to society through the loss of productivity and increased use of health care resources, with decreased patient well-being. ${ }^{50}$

Key drivers in the $\mathrm{CHC}$ economic models are the progression to and the costs associated with advanced liver disease, including $\mathrm{HCC}$. But, two recent studies have reported higher rates of recurrence of HCC in DAA-treated patients compared to what the authors expected in untreated or IFN-treated patients. ${ }^{51,52}$ Nevertheless, a third study (reviewing patients from three French cohorts) showed no increased risk of HCC recurrence. ${ }^{53}$

\section{Conclusion}

The present study sought to contribute to better understanding of the burden associated with HCV infection in Lebanon by estimating the prevalence and the number of deaths that can be attributed to HCV infection and by assessing the health care and societal costs associated with HCV infection under different scenarios of diagnosis and treatment rates. We project that improvements in HCV screening combined with broader access to DAAs can diminish the future clinical and economic burden of $\mathrm{HCV}$ in the Lebanese population and, 
for the middle-aged and elderly, provide the greatest health benefit with net cost savings.

\section{Acknowledgments}

The authors wish to thank Rani Geha, $\mathrm{PhD}$, for providing medical writing and editing services in developing the manuscript. Financial support for these services was provided by AbbVie. The study was a collaboration between AbbVie and all authors. AbbVie had no influence on the conclusion of the study. None of the authors have received financial compensation for writing or authoring this manuscript.

\section{Author contributions}

All authors contributed toward data analysis, drafting and revising the paper and agree to be accountable for all aspects of the work.

\section{Disclosure}

AbbVie authors may own AbbVie stocks or options. Olivier Ethgen owns SERFAN innovation and is a consultant for AbbVie. The authors report no other conflicts of interest in this work.

\section{References}

1. World Health Organization [webpage on the Internet]. Hepatitis $\mathrm{C}$ Fact Sheet; 2017. Available from: http://www.who.int/mediacentre/ factsheets/fs164/en/. Accessed July 2017.

2. Ansaldi F, Orsi A, Sticchi L, Bruzzone B, Icardi G. Hepatitis C virus in the new era: perspectives in epidemiology, prevention, diagnostics and predictors of response to therapy. World J Gastroenterol. 2014;20(29): 9633-9652.

3. Abou Rached A, Abou Kheir S, Saba J, Ammar W. Epidemiology of hepatitis B and hepatitis C in Lebanon. Arab J Gastroenterol. 2016;17(1): $29-33$.

4. Abou Rached A, Abou Kheir S, Saba J, Yaghi C, Ammar W. Prevalence of hepatitis $\mathrm{C}$ and fibrosis stage per age group in Lebanese population. Gastroenterology Insights. 2017;8(1):23-27.

5. Abou Rached A, Yaghi C, Khalil L, Saba J, Ammar W. Prevalence of hepatitis $\mathrm{C}$ virus genotypes and subtypes in Lebanese population and major high risk groups. Arab J Gastroenterol. 2017;18(2):114-117.

6. van der Meer AJ, Veldt BJ, Feld JJ, et al. Association between sustained virological response and all-cause mortality among patients with chronic hepatitis $\mathrm{C}$ and advanced hepatic fibrosis. JAMA. 2012;308(24):2584-2593.

7. Reau N, Vekeman F, Wu E, Bao Y, Gonzalez YS. Prevalence and economic burden of extrahepatic manifestations of hepatitis $\mathrm{C}$ virus are underestimated but can be improved with therapy. Hepatol Commun. 2017;1:439-452.

8. European Association for the Study of the Liver. EASL Clinical Practice Guidelines: management of hepatitis $\mathrm{C}$ virus infection. $J$ Hepatol. 2011;55(2):245-264.

9. Liang TJ, Ghany MG. Current and future therapies for hepatitis $\mathrm{C}$ virus infection. N Engl J Med. 2013;368(20):1907-1917.

10. Reau NS, Jensen DM. Sticker shock and the price of new therapies for hepatitis C: is it worth it? Hepatology. 2014;59(4):1246-1249.

11. Najafzadeh M, Andersson K, Shrank WH, et al. Cost-effectiveness of novel regimens for the treatment of hepatitis C virus. Ann Intern Med. 2015;162(6):407-419.
12. Simon TG, Chung RT. The new hepatitis $\mathrm{C}$ virus bottleneck: can delaying therapy be justified? Hepatology. 2015;62(3):666-667.

13. El Khoury AC, Klimack WK, Wallace C, Razavi H. Economic burden of hepatitis C-associated diseases in the United States. J Viral Hepat. 2012;19(3):153-160.

14. Davis GL, Alter MJ, El-Serag H, Poynard T, Jennings LW. Aging of hepatitis C virus (HCV)-infected persons in the United States: a multiple cohort model of $\mathrm{HCV}$ prevalence and disease progression. Gastroenterology. 2010;138(2):513-521, 521 e511-e516.

15. Gordon SC, Pockros PJ, Terrault NA, et al. Impact of disease severity on healthcare costs in patients with chronic hepatitis $\mathrm{C}(\mathrm{CHC})$ virus infection. Hepatology. 2012;56(5):1651-1660.

16. Pyenson B, Fitch K, Iwasaki K. Consequences of Hepatitis C Virus (HCV): Costs of a Baby Boomer Epidemic of Liver Disease. New York, NY: Milliman, Inc; 2009.

17. Colvin HM, Mitchell AE; Institute of Medicine (US) Committee on the Prevention and Control of Viral Hepatitis Infection. Hepatitis and Liver Cancer: A National Strategy for Prevention and Control of Hepatitis B and $C$. Washington (DC): National Academies Press (US); 2010.

18. Deuffic-Burban S, Schwarzinger M, Obach D, et al. Should we await IFN-free regimens to treat $\mathrm{HCV}$ genotype 1 treatment-naive patients? A cost-effectiveness analysis (ANRS 95141). J Hepatol. 2014;61(1):7-14.

19. Liu S, Cipriano LE, Holodniy M, Goldhaber-Fiebert JD. Cost-effectiveness analysis of risk-factor guided and birth-cohort screening for chronic hepatitis C infection in the United States. PLoS One. 2013;8(3):e58975.

20. Rein DB, Smith BD, Wittenborn JS, et al. The cost-effectiveness of birth-cohort screening for hepatitis C antibody in U.S. primary care settings. Ann Intern Med. 2012;156(4):263-270.

21. Sroczynski G, Esteban E, Conrads-Frank A, et al. Long-term effectiveness and cost-effectiveness of screening for hepatitis $\mathrm{C}$ virus infection. Eur J Public Health. 2009;19(3):245-253.

22. Tramarin A, Gennaro N, Compostella FA, Gallo C, Wendelaar Bonga LJ, Postma MJ. HCV screening to enable early treatment of hepatitis C: a mathematical model to analyse costs and outcomes in two populations. Curr Pharm Des. 2008;14(17):1655-1660.

23. Hagan LM, Yang Z, Ehteshami M, Schinazi RF. All-oral, interferon-free treatment for chronic hepatitis C: cost-effectiveness analyses. $J$ Viral Hepat. 2013;20(12):847-857.

24. Younossi ZM, Singer ME, Mir HM, Henry L, Hunt S. Impact of interferon free regimens on clinical and cost outcomes for chronic hepatitis C genotype 1 patients. J Hepatol. 2014;60(3):530-537.

25. Leigh JP, Bowlus CL, Leistikow BN, Schenker M. Costs of hepatitis C. Arch Intern Med. 2001;161(18):2231-2237.

26. Shah BB, Wong JB. The economics of hepatitis C virus. Clin Liver Dis. 2006;10(4):717-734.

27. Davis KL, Mitra D, Medjedovic J, Beam C, Rustgi V. Direct economic burden of chronic hepatitis $\mathrm{C}$ virus in a United States managed care population. J Clin Gastroenterol. 2011;45(2):e17-e24.

28. Nichols GA, Bell TJ, Pedula KL, O'Keeffe-Rosetti M. Medical care costs among patients with established cardiovascular disease. Am J Manag Care. 2010;16(3):e86-e93.

29. Dall TM, Zhang Y, Chen YJ, Quick WW, Yang WG, Fogli J. The economic burden of diabetes. Health Aff (Millwood). 2010;29(2):297-303.

30. Luo R, Greenberg A, Stone CD. Increasing volume but decreasing mortality of hospitalized hepatitis C patients in the United States, 2005 to 2011. J Clin Gastroenterol. 2015;49(7):620-627.

31. Xu F, Tong X, Leidner AJ. Hospitalizations and costs associated with hepatitis $\mathrm{C}$ and advanced liver disease continue to increase. Health Aff (Millwood). 2014;33(10):1728-1735.

32. Wong JB, McQuillan GM, McHutchison JG, Poynard T. Estimating future hepatitis C morbidity, mortality, and costs in the United States. Am J Public Health. 2000;90(10):1562-1569.

33. Nuno Solinis R, Arratibel Ugarte P, Rojo A, Sanchez Gonzalez Y. Value of treating all stages of chronic hepatitis $\mathrm{C}$ : a comprehensive review of clinical and economic evidence. Infect Dis Ther. 2016;5(4):491-508.

34. Igarashi A, Tang W, Guerra I, Marie L, Cure S, Lopresti M. Cost-utility analysis of ledipasvir/sofosbuvir for the treatment of genotype 1 chronic hepatitis C in Japan. Curr Med Res Opin. 2017;33(1):11-21. 
35. McEwan P, Ward T, Webster S, et al. Estimating the cost-effectiveness of daclatasvir plus asunaprevir in difficult to treat Japanese patients chronically infected with hepatitis C genotype 1b. Hepatol Res. 2016;46(5): 423-433.

36. Younossi ZM, Park H, Saab S, Ahmed A, Dieterich D, Gordon SC. Cost-effectiveness of all-oral ledipasvir/sofosbuvir regimens in patients with chronic hepatitis $\mathrm{C}$ virus genotype 1 infection. Aliment Pharmacol Ther. 2015;41(6):544-563.

37. $\mathrm{Ng} \mathrm{V}$, Saab S. Effects of a sustained virologic response on outcomes of patients with chronic hepatitis C. Clin Gastroenterol Hepatol. 2011;9(11):923-930.

38. Singal AG, Volk ML, Jensen D, Di Bisceglie AM, Schoenfeld PS. A sustained viral response is associated with reduced liver-related morbidity and mortality in patients with hepatitis $\mathrm{C}$ virus. Clin Gastroenterol Hepatol. 2010;8(3):280-288, 288 e281.

39. Linthicum MT, Gonzalez YS, Mulligan K, et al. Value of expanding HCV screening and treatment policies in the United States. Am J Manag Care. 2016;22(6 Spec No.):SP227-SP235

40. Cacoub P, Gragnani L, Comarmond C, Zignego AL. Extrahepatic manifestations of chronic hepatitis $\mathrm{C}$ virus infection. Dig Liver Dis. 2014;46(Suppl 5):S165-S173.

41. Negro F, Forton D, Craxi A, Sulkowski MS, Feld JJ, Manns MP. Extrahepatic morbidity and mortality of chronic hepatitis C. Gastroenterology. 2015;149(6):1345-1360.

42. World Health Organization. Guidelines for the Screening, Care and Treatment of Persons with Hepatitis C Infection. Geneva, Switzerland; 2014.

43. Misurski DA. P0816: reduction in annual medical costs with early treatment of HCV using AbbVie 3D (ABT-450/ritonavir/ombitasvir and dasabuvir) +/- ribavirin in the United States. J Hepatol. 2015;62(1):S642.

44. Semela D, Blach S, Bihl FK, Bruggmann P, Lavanchy D, Negro F. The impact of time on a scenario to minimize complications of hepatitis $\mathrm{C}$ infection. Hepatology. 2014;60:912A.

45. Chhatwal J, Kanwal F, Roberts MS, Dunn MA. Cost-effectiveness and budget impact of hepatitis $\mathrm{C}$ virus treatment with sofosbuvir and ledipasvir in the United States. Ann Intern Med. 2015;162(6):397-406.

46. Igarashi A, Tang W, Cure S, et al. Cost-utility analysis of sofosbuvir for the treatment of genotype 2 chronic hepatitis C in Japan. Curr Med Res Opin. 2017;33(1):1-10.

47. Samp JC, Perry R, Piercy J, Wood R, Baran RW. Patient health utility, work productivity, and lifestyle impairment in chronic hepatitis C patients in France. Clin Res Hepatol Gastroenterol. 2015;39(3):307-314.

48. Chhatwal J, He T, Lopez-Olivo MA. Systematic review of modelling approaches for the cost effectiveness of hepatitis $\mathrm{C}$ treatment with direct-acting antivirals. Pharmacoeconomics. 2016;34(6):551-567.

49. Gonzalez-Grande R, Jimenez-Perez M, Gonzalez Arjona C, Mostazo Torres J. New approaches in the treatment of hepatitis C. World J Gastroenterol. 2016;22(4):1421-1432.
50. El Khoury AC, Vietri J, Prajapati G. The burden of untreated hepatitis C virus infection: a US patients' perspective. Dig Dis Sci. 2012;57(11):2995-3003.

51. Conti F, Buonfiglioli F, Scuteri A, et al. Early occurrence and recurrence of hepatocellular carcinoma in $\mathrm{HCV}$-related cirrhosis treated with direct-acting antivirals. J Hepatol. 2016;65(4):727-733.

52. Reig M, Marino Z, Perello C, et al. Unexpected high rate of early tumor recurrence in patients with $\mathrm{HCV}$-related $\mathrm{HCC}$ undergoing interferonfree therapy. J Hepatol. 2016;65(4):719-726.

53. ANRS Collaborative Study Group on Hepatocellular Carcinoma. Lack of evidence of an effect of direct-acting antivirals on the recurrence of hepatocellular carcinoma: data from three ANRS cohorts (ANRS CO22 HEPATHER, CO12 CirVir and CO23 CUPILT cohorts). J Hepatol. 2016;65(4):734-740.

54. Thein HH, Yi Q, Dore GJ, Krahn MD. Estimation of stage-specific fibrosis progression rates in chronic hepatitis $\mathrm{C}$ virus infection: a metaanalysis and meta-regression. Hepatology. 2008;48(2):418-431.

55. Liu S, Cipriano LE, Holodniy M, Owens DK, Goldhaber-Fiebert JD. New protease inhibitors for the treatment of chronic hepatitis C: a costeffectiveness analysis. Ann Intern Med. 2012;156(4):279-290.

56. Alazawi W, Cunningham M, Dearden J, Foster GR. Systematic review: outcome of compensated cirrhosis due to chronic hepatitis $\mathrm{C}$ infection. Aliment Pharmacol Ther. 2010;32(3):344-355.

57. Razavi H, Elkhoury AC, Elbasha E, et al. Chronic hepatitis C virus (HCV) disease burden and cost in the United States. Hepatology. 2013;57(6): 2164-2170.

58. Singal AK, Singh A, Jaganmohan S, et al. Antiviral therapy reduces risk of hepatocellular carcinoma in patients with hepatitis $\mathrm{C}$ virus-related cirrhosis. Clin Gastroenterol Hepatol. 2010;8(2):192-199.

59. Thuluvath PJ, Guidinger MK, Fung JJ, Johnson LB, Rayhill SC, Pelletier SJ. Liver transplantation in the United States, 1999-2008. Am J Transplant. 2010;10(4 Pt 2):1003-1019.

60. Jacobson IM, McHutchison JG, Dusheiko G, et al; ADVANCE Study Team. Telaprevir for previously untreated chronic hepatitis $\mathrm{C}$ virus infection. N Engl J Med. 2011;364(25):2405-2416.

61. Poordad F, McCone J Jr, Bacon BR, et al. Boceprevir for untreated chronic HCV genotype 1 infection. N Engl J Med. 2011;364(13):1195-1206.

62. Lawitz E, Mangia A, Wyles D, et al. Sofosbuvir for previously untreated chronic hepatitis C infection. N Engl J Med. 2013;368(20):1878-1887.

63. Ferenci P, Bernstein D, Lalezari J, et al. ABT-450/r-ombitasvir and dasabuvir with or without ribavirin for HCV. N Engl J Med. 2014;370(21): 1983-1992.

64. Feld JJ, Kowdley KV, Coakley E, et al. Treatment of HCV with ABT-450/r-ombitasvir and dasabuvir with ribavirin. $N$ Engl J Med. 2014;370(17):1594-1603.

65. Poordad F, Hezode C, Trinh R, et al. ABT-450/r-ombitasvir and dasabuvir with ribavirin for hepatitis C with cirrhosis. NEngl J Med. 2014;370(21) 1973-1982.
Hepatic Medicine: Evidence and Research

\section{Publish your work in this journal}

Hepatic Medicine: Evidence and Research is an international, peerreviewed, open access journal covering all aspects of adult and pediatric hepatology in the clinic and laboratory including the following topics: Pathology, pathophysiology of hepatic disease; Investigation and treatment of hepatic disease; Pharmacology of drugs used for the treatment
Submit your manuscript here: https://www.dovepress.com/hepatic-medicine-evidence-and-research-journal

of hepatic disease. Issues of patient safety and quality of care will also be considered. The manuscript management system is completely online and includes a very quick and fair peer-review system, which is all easy to use. Visit http://www.dovepress.com/testimonials.php to read real quotes from published authors. 